\title{
Significance of the Easy-to-use Water Quality Checker for Participative Environmental Monitoring and Experience Based Learning
}

\author{
Akira Kikuchi $^{*}$, Luchman Hakim ${ }^{2}$, Arien Heryansyah ${ }^{1}$, Romaidi $^{3}$ \\ ${ }^{1}$ Institute of environmental and water resources Management, Universiti Teknologi Malaysia, Skudai Johor, Malaysia \\ ${ }^{2}$ Faculty of Mathematics and Natural Science, University of Bravijaya, Indonesia, Malang, East Java, Indonesia \\ ${ }^{3}$ Faculty of Science, Universitus Islam Negeri Malang, Indonesia, Malang, East Java, Indonesia
}

\begin{abstract}
Pack Test is a series of products of Kyoritsu Chemical-Check Laboratory Cooperation, Japan. It is easy-to-use, anybody can use at anywhere, low cost, nontoxic, safe, and professional-use, onetime use ion-selective color metric water quality checker. The aim of this research is to assess, then next, discuss the significance of applications of this tool. In this order, $\mathrm{NH}_{4}$-Pack Test was selected as an example for the discussions; although there are more than 60 parameters can be detected by pack test such as, $\mathrm{COD}, \mathrm{Cl}^{-}, \mathrm{NO}_{3}{ }^{-}$, phosphate, hardness, $\mathrm{pH}$, heavy metals, etc.. As for field survey, Ion chromatography was used to measure ammonium concentration of river water in Jakarta. Then detection range of the $\mathrm{NH}_{4}$-Pack Test was compared to the data, and Indonesian and Malaysian national water quality standard. River water quality of Jakarta was weekly degraded at upstream area, but it was seriously degraded at downstream area (up to 5-10 $\mathrm{NH}_{4}-\mathrm{N} \mathrm{mg} / \mathrm{L}$ ). As for ammonium concentration, obviously the detection range and step of Pack Test was sufficient to assess the ammonium concentrations of rive water in Jakarta. Of course Pack Test is very simplified tool, environmental water quality standard of ammonia for class I in Indonesia and Class I and II in Malaysia were difficult to evaluate. However, it was obviously applicable to check treated effluent and Class III to V water quality of Malaysian environmental standard. Consequently, it is suggested to adopt a double standard policy of water quality monitoring, such as combination of "easy-to-use simplified" and "conventional-accurate". Because of low cost, and professionalconvenient design, implementation of Pack Test will significant to empower on-site water quality monitoring in developing country, participative environmental awareness public programs, experience base environmental learning in schools, and other grass-rooted environmental activities.
\end{abstract}

Keywords: Environmental awareness and education, Pack test, Simplified method, Southeastern Asian county

\section{Introduction}

Nature is self-organizing system, and its information is expressed by a mechanism, and storing information means increasing the complexity of the mechanism [1]. From the concept of evolutional stable strategy [2], human being, as a part of nature, has packed prodigious number of interrelated mechanisms by virtue of built-in regulatory circuits, and sufficiently has opened to carry into the future a promise of new developments. However development of human's society has coursed environmental problems that are inconvenient internal perturbations occurred in socio- environmental complex level, which act as external perturbations on each personal life. According

\section{*Corresponding address:}

Akira Kikuchi

Institute of environmental and water resources

Management, Universiti Teknologi Malaysia 81310,

Skudai Johor, Malaysia

Email : kikuchiakira@hotmail.com to the concept of robustness theory, living system has a mechanism as its functions to against the both internal and external perturbations [4]. Here, Carison and Doyle [5-6] have argued that systems have evolved to higher level of complexity are optimized for specific perturbations but, at the same time, are also inevitably extremely fragile to asymptotic perturbations. In line with this, it can be assumed that criticism of socio-environmental complexity may take a role to increase robustness of human being. In this paper we would like to discuss the criticism of human's society, taking an example on a water quality check tool towards the environmental conservation act from educational point of view.

Leaner-centered practices in educational contexts can provide insights into experience base (e-) learning from learner-centered principles [7]. This e-learning has been defined as "the use of information and communications technology to support learning [8]. Here, according to the general teaching/learning definition, teaching is curriculum base, teacher 
centralized education. In line with this, if the top down scheme simply educate students as information consumers, it could be assumed that students became sympathizer or bystander to environmental acts. On the other hand, elearning processes would enable the student's self-motivated, and then the students were required to be as information creators with criticism. Next, from a viewpoint of decision making processes, environmental decisionmaking hierarchy is generally composed of four levels, such as Policy $=>$ Plan $=>$ Program $=>$ Project [9]. As one moves down the hierarchy from policies to project, the nature of decisionmaking changes which has prescribed specifications. On the contrary, the process at policy, plan, and program (PPP) level tends to deal with more flexible proposals with wider range of scenarios toward the broader goals. If it needs to concern the criticism on social level problem, accordingly, early environmental assessment with decision-making processes at PPP level is being more required.

According to a World Bank Report for the new challenging assessment [10], suitable tools for strategic environmental decision making process require these characters at least, as follows, a) Simple and available character for participatory assessment that can operate even in situations of significant data gaps; b) enhancing quality of inter-institutional consultations during the planning processes. These characters are rightfully suitable for experimental base learning too. Here, it is already scoped that it is very important to prepare such tools for strategic environmental decision making process and elearning via market-based instruments, it will enables to enhance the self-motivated environmental act especially in rapidly developing Asian countries.

In this paper, stream water quality of Jakarta was concerned as an example of environmental problem, and then simplified water quality checker were introduced to enhance the elearning and strategic environmental assessment to concern water environment restoration in southeastern Asian countries.

\section{Methods for field survey}

Ion separation was performed on a Tosoh Model IC-2001 (Tosoh, Tokyo, Japan). The separation were carried out using polymethacrylate-based weakly acidic cation- exchange resin columns in the $\mathrm{H}^{+}$-form: TSKgel Super-IC-A/C (3 micro $m$ particle size, 0.2 mequiv./ml cationic exchange capacity, 150x6.0 $\mathrm{mm}$ I.D.). The experimental conditions for ion chromatography (IC) were as follows: column temperature 40 degree C., effluent such as $6 \mathrm{mM}$ tartaric acid and $3 \mathrm{mM}$ 18-crown-6/methanol water, effluent flow rate $0.6 \mathrm{ml} / \mathrm{min}$, and injection volume 100 micro 1 (Mori et al. 2003, Masuda et al. 2007). Stream water samples were collected from 17 sites along two streams in Jakarta on March, 2009 (Figure 1). The Jakarta area is covered less than $1 \%$ by sewage system (hearing from PDPAL Jaya) and stream water is visibly degraded flowing through the city area. Each water samples were filtered by 0.2 micro $\mathrm{m}$ membrane filter (DISMI-25HP, Advantech Toyo Kaisha, Ltd.) immediately, and then stored in a plastic bottle for IC2001. The measured water quality data were compared to Indonesian (Gov. Regulation 82/2001, and Ministerial Decree No Kep-51/Menlh/10/1995) and Malaysian (DOE) water quality standard for surface water, respectively.

\section{Result}

The concentration of $\mathrm{SO}_{4}^{2-}, \mathrm{Cl}^{-}, \mathrm{NO}_{3}^{-}, \mathrm{Na}^{+}$, $\mathrm{NH}_{4}{ }^{+}, \mathrm{K}^{+}, \mathrm{Mg}^{2+}, \mathrm{Ca}^{2+}$ for each samples were simultaneously analyzed. The concentrations of ammonium were shown in Fig. 2. As always visibly being recognized the river water degradation, the concentrations of the ammonium ions increased dramatically towards downstream in Jakarta. The concentrations of ammonium were higher in branch (site 1 to 10) while it is lower in the main stream of Ciliwung river (11 to 17). As for ammonium concentrations of upstream zone, the main stream of Ciliwung River (at site 11 and 12) was compared to Class I of Indonesian regulation (Governmental Regulation No.82/2001) and class II for Malaysian regulation (DOE). The water quality is sufficient as raw material supply for drinking water. On the contrary, for the branch of Ciliwung river, all the points are compared to the Indonesian regulation of treated effluent (Ministerial Decree No Kep51/Menlh/10/1995), and Class IV for Malaysian regulation which just could be irrigation use. Then, after the water flow through the Jakarta, the water quality becomes almost same with raw waste water that is compared to Class $\mathrm{V}$ of Malaysian regulation (extremely degraded). 


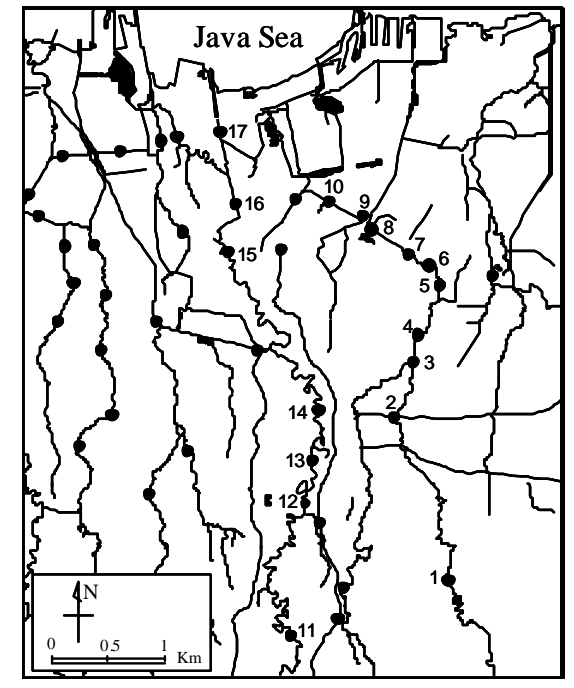

Figure. 1. Sampling sites of river water in Jakarta, Indonesia. a)

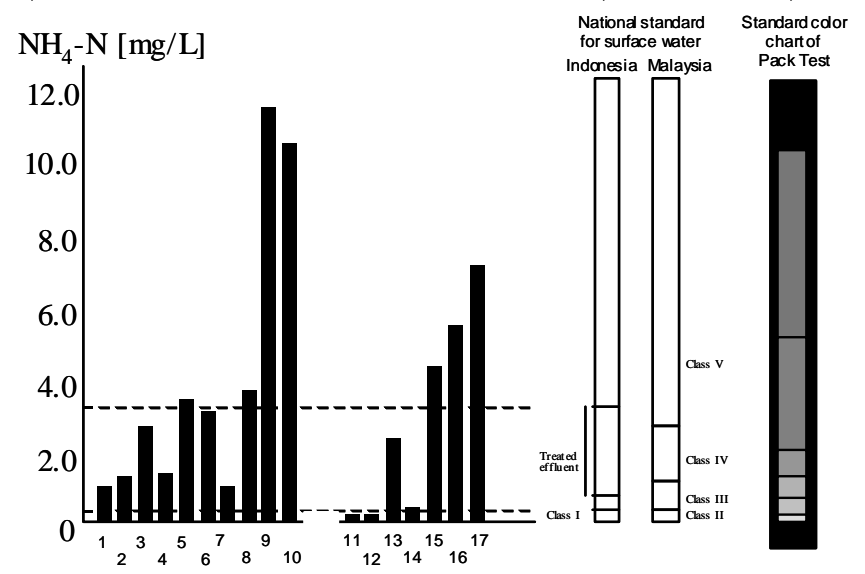

Figure. 2. a) Ammonium concentrations of stream water in Jakarta. Sampling points are shown in figure 1. b) Water quality standards of Indonesia and Malaysia. c) Standard color chart of ammonium for Pack Test.

\section{Discussion}

In this research, water qualities were measured by liquid ion chromatography, which is accurate and minimum detection level also good, e.g. $0.016 \mathrm{mg} / \mathrm{L}$ for ammonium-N [3]. However special equipment, technician, and well-managed laboratory are required to analyze water samples. On the other hand, because of demand from water-environmental authority and their technician, simplified water quality analysis also has developed [e.g. 11, 12]. In line with regarding, Kyoritsu chemical-check Lab. Corp.'s ion selective Pack Test (hereinafter, referred as "Pack Test" is considered to be the most simplified professional use water quality testing tool in the world. Then, first of all, the detection range of standard color chart and governmental regulations are compared in figure 2. Obviously the detection range of standard color chart of the Pack Test is sufficient to assess the ammonium concentrations of Ciliwung River, and is possible to assess the water environment by Indonesian and Malaysian water quality standard for treated effluent and surface water. Of course the Pack Test is color metric visual obstruction method (Figure 3.), so that it may be difficult to argue the significance the water quality difference as for low concentration zone, i.e. for Class I in Indonesia and Class I and II in Malaysia. However it admirably indicates the Pack Test is applicable to assess water environment for wastewater checking in Indonesia and Class III to $\mathrm{V}$ water body in Malaysia, for the ammonium concentrations.

As for ammonium concentration, it can be concluded that conventional water quality analysis by national industrial standard is required for excellent quality of water body, moreover from another point of fact, it can be suggested that simplified method such as Pack Test is also applicable to assess the water quality monitoring for waste water checking and degradation of raw water resources monitoring. To adopt such as "conventional-accurate" and "easy-to-use simplified" double standard policy for water quality monitoring will be significant to empower on-site stream water quality monitoring, environmental education, and water quality monitoring by facility limited laboratories. In addition, to improve the risk of visual obstruction process, Kyoritsu chemical-check $\mathrm{Lab}$ is already developed their market base mobile onsite spectrophotometer.

The user-friendly design of Pack Test can be considered to enhance the quality of interpersonal/institutional self-consultations during the planning processes, which means the Pack. Test has high potential for strategic environmental assessment for water environmental issues. On the other hand, from a view point of e-learning [7], the character of Pack Test is convenient for personal experiment, i.e. elementally school students also can examine water environmental problems and can interpret 
(1) Remove the colored line at the top of the tube to clear the aperture.

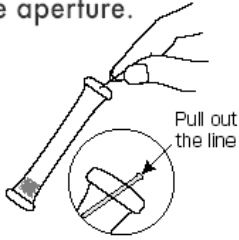

(4) Shake the tube slowly a few times.

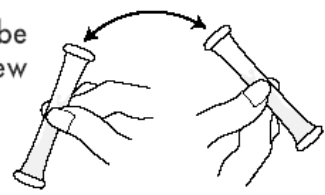

(2) Press tube's side wall to expel air, and hold the tube.

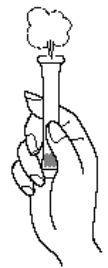

(3) Immerse the aperture of the tube into the sample fluid and release to fill the tube halfway.

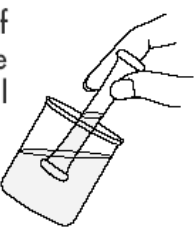

(5) Wait for the reaction time as indicated in the instruction manual then compare the actual color in the tube with provided Standard Color sheet.

Nearest color indicates the concentration of the analyte in your sample.

Figure 3. How to use Pack Test (from Kyoritsu chemical-check Lab. Corp.).The character of the Pack Test is rapid, easy to use, small, nontoxic, safety, low-cost, and anyone can use anywhere without any laboratory facilities. The menu is available more than 60, and almost all measurements can be carried out within 5 minutes. These characters are concluded as availability for simpleconvenient, onsite and participative analysis.

it from own experiment, and can consider the solution by themselves, with small support. In regarding with this function, manual book in Japanese [e.g. 11] and in English [12] are always available. Moreover, after the almost 40 years experience, not only $\mathrm{NH} 4$, but also other parameter, such as $\mathrm{COD}, \mathrm{Cl}^{-}, \mathrm{NO}_{3}-\mathrm{Mg}^{2+}, \mathrm{Ca}^{2+}$, phosphate, hardness, $\mathrm{pH}$, heavy metals, and other parameters, in total, more than 60 menus are available (Table S.4.1).

As for application of Pack Test for aerial environmental monitoring, if there are 60 participants, for example, 15 teams may be formed. Then if each team observes five sites in a short time, it is simultaneous 75 sites environmental monitoring with 60 brains with 120 eyes. Moreover, after the on-site experiments and fieldwork, participants can discuss the status of water qualities and the relationship between human's attitudes from the recorded result and their experience of each charged area. Then after the overview and reasons of the water problem become clear, participant can consider solution to protect or to restore the water environment and the information can be reported to other peoples in order to enhance their awareness. Of course in reality, to implement the solutions, it is necessary the budget, knowledge, skills, public commitment, personal efforts, and so on. However once the problem status has recognized that environmental problems turn into a social level internal perturbations that act as external perturbations on each personal life too, vice versa, positive participation for environmental education and activity are fundamentally required to tackle such problems.
In this point of fact, the Pack Test is defined as the most simplified water quality analyzer, which has potential to enhance the e-learning for environmental matter, and that is applicable for environmental workshops which realize regional wisdom for water-environment management. In this definition the Pack Test is considered as an inevitable meaningful tool of information and communications technology to improve the environmental criticism because it may take a role to manage robustness of our socioenvironmental complex. If such an aspect is distinguished, the Pack Test will be a tool which let not public environmental monitoring data be in only research institute but put it in public, and never being cheap articles but rather professional environmental monitoring tool with wide application.

Although it accounts for only $23 \%$ of the world's total land area, about $58 \%$ of the world's population lives in the Asia-Pacific region [13] The economies of this region have experienced high growth rates in the recent past. As water environment in Jakarta indicate, aquatic environment degrade in spite of the economic development. Accordingly, to strength the environmental education towards the wisdom for water environmental conservation, we suggest to implement the Pac Test with confirmation by national industrial standards from new socio-environmental regulation aspect in Indonesia and other rapidly developing Asian countries. In that case, to develop small model of application project will be very important issue for initial implementation stage in each country and region. 


\section{Acknowledgement}

The authors thank Kyoritsu Chemical-Check Lab., Corp. for support to provide data of Pack test, and their kind preparation of Figure 3 and Appendix. Moreover we deeply have impressed with their personal honesty, and their unquestionable attitude of social responsibility of their company.

Reference

[1] Margalef R. Perspectives in Ecological Theory, The University of Chicago, Illinois, USA. 1968.

[2] Maynard Smith J, Price GR. The logic of animal conflict. Nature 1973; 246: 15-18.

[3] Masuda W, Tanaka K, Goto R, Hasebe K, Kikuchi A, Nakagoshi N. Ion-exclusion/cation-exchange chromatography for water quality monitoring of river waters, Journal of Japan Industrial Water Association 2007; 585: 80-86. (in Japanese)

[4] Kitano H. Biological robustness. Nature Review Genetics 2004; 5: 826-837.

[5] Carison JM, Doyle, J. Highly optimized tolerance: a mechanism for power laws in designed systems. Physical Review E 1999; 60: 1412-1427.
[6] Carison, J.M. \& Doyle, J. Complesity and robustness. Proceedings of Natural Academic Science USA 2002; 99 (suppl 1): 2583-2545.

[7] Mc Combs, B.L. A framework for the Redesign of $\mathrm{K}-12$ Education in the Context of Current Educational Reform, Theory into Practice 2003; 42: 93-101.

[8] Usoro, A. \& Abid, A. Conceptualizing Quality Elearning Higher Education, E-learning 2008; 5: 75-88.

[9] OECD. Applying Strategic Environmental Assessment Good practice guidance for development co-operation, DAC Guidelines and Reference Series, OECD Publishing, USA. 2006.

[10] World Bank. Strategic Environmental Assessment in east and Southeast Asia - A progress Review and Comparison of Country System and Cases, The World Bank, USA. 2006.

[11] Okauchi, K. Environmental survey by Pack Test-anybody can do. Godo-syuppan, Japan (in Japanese). 2000.

[12] Global Environmental Centre Foundation (GECF). Manual for Environmental Preservation Activities Focused on Revers (2 $2^{\text {nd }}$ Edition), Global Environmental Centre Foundation, Japan. 2004.

[13] Economic and Social Commission for Asia and the Pacific (ESCAP). The State of the Environment in Asia and the Pacific. Bangkok: Economic and Social Commission for Asia and the Pacific. 1995. 